\title{
Study on a Soaking Process of Nitroguanidine Propellant
}

\author{
ZHANG Xuan ${ }^{1, a}$, CHEN Ming-lei ${ }^{1, b}$, XING Ruo-ting ${ }^{1, c}$, ZHANG Bo $^{1, d}$, WANG \\ $\mathrm{Na}^{1, \mathrm{e}}, \mathrm{LI}$ Ling-di ${ }^{1, f}, \mathrm{CHAO} \mathrm{Hui}^{1, g}$, SUN Jun-Wei ${ }^{2, \mathrm{~h}}$ \\ ${ }^{1}$ Gansu Province Yinguang Chemical Industry Group Co., Ltd, Baiyin 730900, China \\ ${ }^{2}$ School of Chemical Engineering,NUST, Nanjing 210094, China

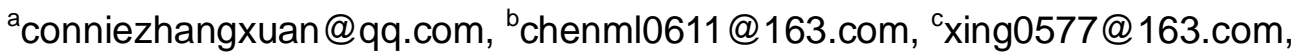 \\ dzhang0522@163.com, ${ }^{\mathrm{d}}$ nawang@sina.com, ${ }^{\mathrm{f}}$ chaohui@sioc.ac.cn, ${ }^{9}$ junwei@foxmail.com
}

Keywords: nitroguanidine triple-base propellant, soaking process

Abstract: In order to increase the surface area of the Nitroguanidine triple-base propellant, and to improve the initial burning rate, lower ignition limit pressure, through a combination of propellant specific characteristics, to determine the appropriate soaking process, to make the surface of the propellant of a sufficient microporous, and finally determine the soaking conditions.

\section{Introduction}

According to the literature ${ }^{[1]}$, when the temperature is $100^{\circ} \mathrm{C}, 9 \mathrm{~g}$ nitroguanidine can be dissolved in $100 \mathrm{~g}$ water, and the same temperature, the solubility of nitrocellulose and nitroglycerin is small, can be ignored. Design of experiments, soaked with boiling water nitroguanidine propellant, will launch nitroguanidine drug dissolved away part of the surface, changing the nitroguanidine emitting surface structure of drug-based propellant, let nitroguanidine propellant surface a lot of holes, improving fuel face, lower ignition limit pressure, improve initial nitroguanidine propellant burning rate and improve chamber pressure.

The purpose is to increase the surface area of the flooding process of propellant to raise the initial burning rate, lower ignition limit pressure. While propellant must have a certain size and shape to meet the requirements of propellant ballistic performance ${ }^{[2]}$. Therefore, we must combine nitroguanidine propellants specific characteristics, to determine the appropriate soaking process, making the surface of propellant enough pores formed at the same time, its structure will not change much, the performance will not be a big impact, at the same time also we need to take into account productivity and controllable ${ }^{[3-5]}$.

\section{Experimental}

Materials and equipment. HH-1 type digital thermostat water bath (Shanghai Ye Ta Instrument Co., LTD), JH2500 kneader, (Shanghai Red star Chemical Machinery Factory), Closed-bomb, SEM(FEI Quanta 250), self-made propellant mold and cutter.

The flooding of triple-base propellant formed under the above conditions compared temperature; immersion and time were measured and analyzed the experimental data.

\section{Results and discussion}

Select Propellant state. How much of the solvent content of propellant prepared a large impact on 
the flooding process. To master the appropriate soaking process, respectively, drive propellant solution were studied before and after immersion tests. With not drive solution propellant soaking their state is shown in Figure 1a, seen from the figure, the propellant surface appeared a large number of bubbles, drug type structural changes lead to the destruction of the original structure. This is due to the pressing out of the propellant, but also the remaining $15 \%$ of the alcohol and ketone solvents, the powder in this state into an aqueous solution of a higher temperature, the solvent volatilized into a gas heated on the one hand, on the other hand a solvent soluble in water. Internal solvent evaporation into a gas and can not be immediately removed, bubbles formed inside, resulting in damage to the structure of propellant. Surface layer solvent soluble in water, and the internal solvent to form a concentration gradient, accelerated migration of the solvent, resulting in structural damage propellant. And after propellant driven solution remaining after less solvent, and the density of the whole structure of propellant has been formed, thus flooding the structure of the process will not cause damage propellants. See Figure 1.

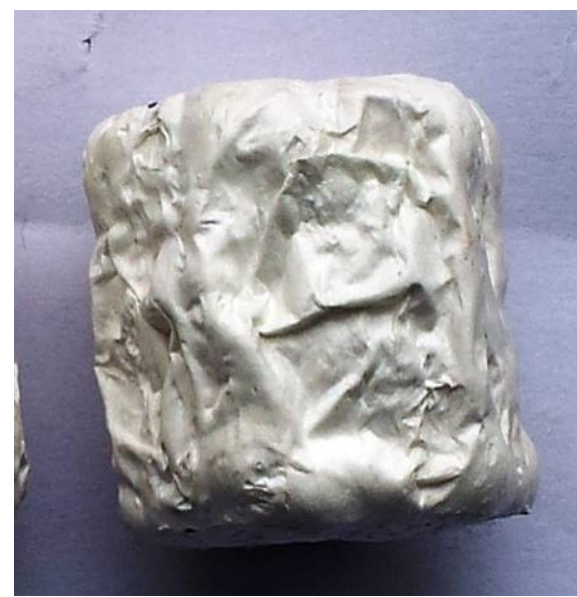

Figure 1 (a) after flooding of an insoluble propellant

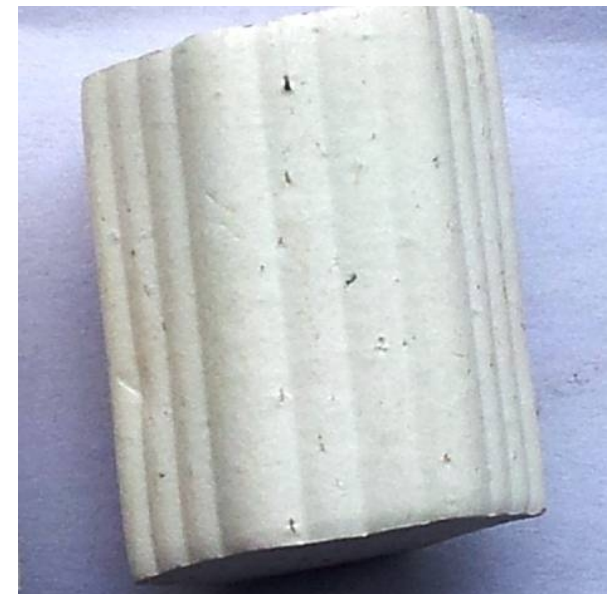

Figure. 1 (b) after flooding in the solution of the propellant

Therefore, although not through drive solution for soaking treatment can simplify the process, but the launch of the propellant structure has been destroyed, to launch the mechanical properties of the propellant and combustion performance has seriously affected. Therefore, it should be make immersion test by flooding after the dissolution of the propellant.

\section{The choice of soaking temperature}

We can see from Table 1, the solubility of nitroguanidine at 80 DEG C after large, so the temperature of immersion in water between 80 100 DEG C. The samples were soaked in water at 80, 90 and 100 respectively, and the soaking time was 10 60min, and the sample was taken at every $10 \mathrm{~min}$.

Among them, Table 1 is the loss rate of mass, the mass loss of the unit area is 3.2.

The experimental results of mass loss and immersion time of the drug delivery are as follows.

Table 1 The relationship between weight loss rate and immersion temperature of propellant

\begin{tabular}{lllllll}
\hline Time/min & 10 & 20 & 30 & 40 & 50 & 60 \\
\hline $80^{\circ} \mathrm{C}$ & $1.0952 \%$ & $1.2996 \%$ & $1.5641 \%$ & $1.6261 \%$ & $1.8088 \%$ & $1.8905 \%$ \\
$90^{\circ} \mathrm{C}$ & $1.3455 \%$ & $1.7901 \%$ & $2.0018 \%$ & $2.2043 \%$ & $2.2881 \%$ & $2.5162 \%$ \\
$100^{\circ} \mathrm{C}$ & $1.6887 \%$ & $2.1207 \%$ & $2.4972 \%$ & $2.7387 \%$ & $3.0496 \%$ & $3.2427 \%$ \\
\hline
\end{tabular}


Table 2 Leaching per unit area at different temperatures (unit: $\mathbf{m g} / \mathrm{cm} 2$ )

\begin{tabular}{lllllll}
\hline Time/min & 10 & 20 & 30 & 40 & 50 & 60 \\
\hline $80^{\circ} \mathrm{C}$ & 4.5678 & 5.4331 & 6.5067 & 6.7513 & 7.5609 & 7.8733 \\
$90^{\circ} \mathrm{C}$ & 5.5979 & 7.4545 & 8.4099 & 9.1460 & 9.5106 & 10.4524 \\
$100^{\circ} \mathrm{C}$ & 7.0675 & 8.8075 & 10.4550 & 11.3786 & 12.4521 & 13.3594 \\
\hline
\end{tabular}

As Table 1 data shows, with the increase of soaking and cooking time, the weight loss increased; the higher the temperature, weight loss is greater, the solubility of such features and nitroguanidine accord with the characteristics of; data in Table 2, indicating that extract the higher the temperature, the shorter the duration of leaching quantity of the corresponding nitro guanidine, there is conducive to the process of implementation, improve production efficiency. Considering the degree of treatment and treatment efficiency, selection of immersion temperature is 100 DEG C. Immersion effect of leaching effect of propellant.

Powder and extract quality ratio (m): theoretical analysis and 100 DEG C nitroguanidine solubility in water for $10.36 \mathrm{~g} / 100 \mathrm{~g}$, and nitro guanidine guanidine-15 powder which accounts for mass fraction is about 47 per cent, so that $100 \mathrm{~g}$ of water can be dissolved $22.04 \mathrm{~g}$ three guanidine - 15 gunpowder in nitro guanidine composition about ratio of about 5:1. Therefore, the value of the powder and extract the mass ratio of less than 1:5.

In order to change the infusion research in the soaking process of immersion process, experiments as follows:

Process(1). First group triple base propellant drying to constant weight, weighing, immersion test, water control for micro boiling, to maintain the water temperature is $100 \mathrm{DEG} \mathrm{C}$, water $400 \mathrm{ml}$. After a period of time, the interval was removed and then weighed, and then soaked in water. Test results are shown in table 3 .

Table 3 the relationship between the quality of the same sample and soaking time

\begin{tabular}{|c|c|c|c|c|c|c|c|}
\hline $\begin{array}{l}\text { Soaking time } \\
\text { t/min }\end{array}$ & 0 & 30 & 60 & 90 & 120 & 150 & 180 \\
\hline $\begin{array}{l}\text { Sample quality } \\
\mathrm{m} / \mathrm{g}\end{array}$ & 1.6921 & 1.6058 & 1.5871 & 1.5830 & 1.5791 & 1.5670 & 1.5660 \\
\hline
\end{tabular}

The quality of the water immersion after the curve of the process is shown in figure 3.2.

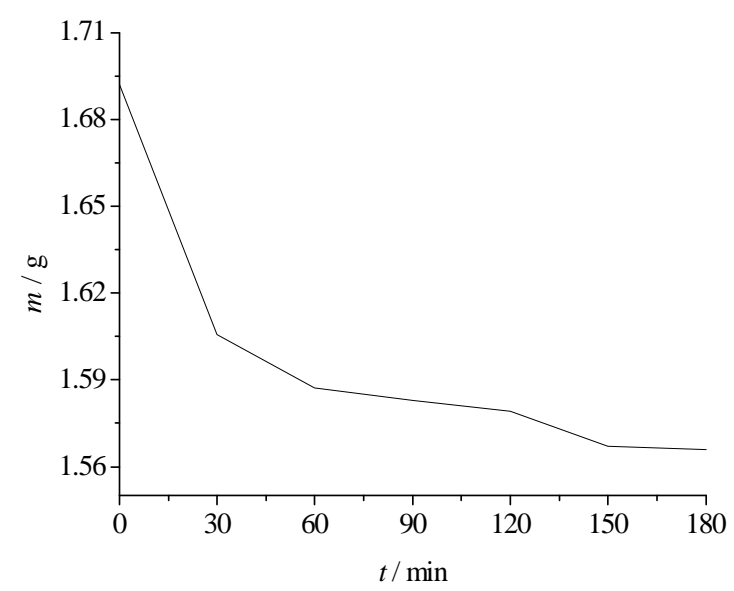

Fig. 2 Change of water quality in the same sample

The same sample can be seen in the process of soaking, with the increase of soaking time and the 
loss of quality tends to zero. The maximum value of the water quality of the drug delivery is the maximum, and the basic no longer changes with the immersion time.

Process(2). The first the same soaking process, the boiled control status is the micro boiling, temperature of $100 \mathrm{DEG} \mathrm{C}$, water $400 \mathrm{ml}$ of soaking process, but flooding the selected time intervals during does not replace the extracts. Quality changes as shown in table 4.

Table 4 not for water in the process of water immersion

\begin{tabular}{|c|c|c|c|c|}
\hline $\begin{array}{l}\text { Water boiling time } \\
\mathrm{t} / \mathrm{min}\end{array}$ & $\begin{array}{l}\text { Pre cook weight } \\
\mathrm{m} / \mathrm{g}\end{array}$ & $\begin{array}{l}\text { Cook back weight } \\
\mathrm{m} / \mathrm{g}\end{array}$ & $\begin{array}{l}\text { Weightlessness } \\
\Delta \mathrm{m} / \mathrm{g}\end{array}$ & $\begin{array}{l}\text { Weight loss rate } \\
\Delta \mathrm{m} / \mathrm{m} / \%\end{array}$ \\
\hline 30 & 12.9557 & 12.7044 & 0.2513 & 1.9379 \\
\hline 60 & 12.2508 & 11.9499 & 0.3009 & 2.4562 \\
\hline 90 & 13.0257 & 12.6369 & 0.3888 & 2.9849 \\
\hline 120 & 11.8593 & 11.4076 & 0.4517 & 3.8088 \\
\hline 150 & 11.5170 & 11.0708 & 0.4462 & 3.8743 \\
\hline 180 & 12.9250 & 12.4060 & 0.5190 & 4.0157 \\
\hline
\end{tabular}

Process (3). The process water heat exchangers in the soaking process, namely: refers to every 30 minutes to come up with a single sample, decoct medicinal herbs are replaced with boiling water to prepare in advance of the water. Quality changes as shown in table 5.

Table 5 Replace the infusion in the soaking process

\begin{tabular}{|c|c|c|c|c|}
\hline $\begin{array}{l}\text { Water boiling time } \\
\text { t/min }\end{array}$ & $\begin{array}{l}\text { Pre cook weight } \\
\qquad \mathrm{m} / \mathrm{g}\end{array}$ & $\begin{array}{c}\text { Cook back weight } \\
\text { mg }\end{array}$ & $\begin{array}{c}\text { Weightlessness } \\
\qquad \Delta \mathrm{m} / \mathrm{g}\end{array}$ & $\begin{array}{l}\text { Weight loss rate } \\
\qquad \Delta \mathrm{m} / \mathrm{m} / \%\end{array}$ \\
\hline 30 & 12.0340 & 11.8230 & 0.2110 & 1.7534 \\
\hline 60 & 12.0330 & 11.7402 & 0.2928 & 2.4333 \\
\hline 90 & 12.3600 & 12.0022 & 0.3578 & 2.8948 \\
\hline 120 & 12.9929 & 12.5561 & 0.4368 & 3.3618 \\
\hline 150 & 13.8046 & 13.2785 & 0.5261 & 3.8110 \\
\hline 180 & 13.0741 & 12.5555 & 0.5186 & 3.9667 \\
\hline
\end{tabular}

Two kinds of water immersion process, the weight loss process is as follows: 


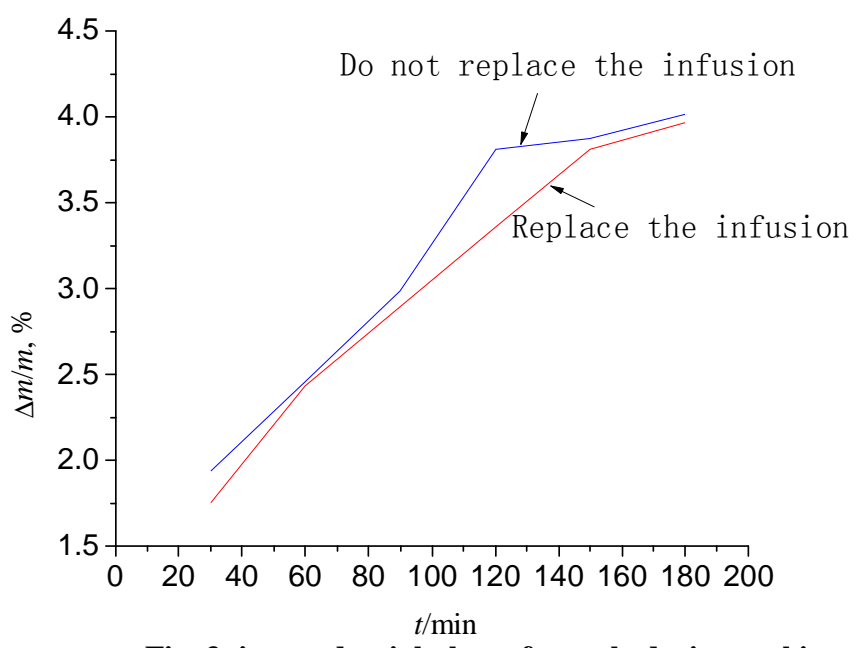

Fig. 3 time and weight loss of sample during soaking

From figure 3 can be seen in the boiling process, changing the water and does not change the water had little effect on the weightlessness of medicine, and infusion of continuous use of the specimen weightlessness rate faster. The immersion liquid continuous use for process simplification, improve production efficiency. Therefore, experiment is followed by does not change the water in the process.

\section{Choice of soaking time}

It is very important to use boiling water to surface treatment of the propellant. The soaking time is too short, could not be formed on the surface enough of the microporous structure, surface area did not increase obviously, fail to achieve the ideal effect; and soaking time is too long, nitro guanidine amount of dissolved, energetic component loss too much, will make the emission medicine energy fell sharply, affected the ballistic effect fruit.

In order to achieve the purpose of the experiment and not to affect the ballistic effect, the quality of the 1\% 3\% should be controlled in the immersion of the nitro group. Therefore, the change of the quality of the drug delivery is as follows:

(1) Shorten the time interval of water boiling for $15 \mathrm{~min}$. The remaining conditions are in the same process (two), and the quality changes as shown in table 6 .

Table 6 changes in the quality of powder in the process of water immersion (interval 15min)

\begin{tabular}{|c|c|c|c|c|}
\hline $\begin{array}{l}\text { Water boiling time } \\
\qquad \mathrm{t} / \mathrm{min}\end{array}$ & $\begin{array}{l}\text { Pre cook weight } \\
\qquad \mathrm{m} / \mathrm{g}\end{array}$ & $\begin{array}{c}\text { Cook back weight } \\
\text { m'/g }\end{array}$ & $\begin{array}{l}\text { Weightlessness } \\
\qquad \Delta \mathrm{m} / \mathrm{g}\end{array}$ & $\begin{array}{l}\text { Weight loss rate } \\
\qquad \Delta \mathrm{m} / \mathrm{m} / \%\end{array}$ \\
\hline 15 & 11.5383 & 11.3508 & 0.1875 & 1.6325 \\
\hline 30 & 10.3122 & 10.0455 & 0.2667 & 2.5863 \\
\hline 45 & 10.6819 & 10.3666 & 0.3153 & 2.9517 \\
\hline 60 & 11.3585 & 10.9908 & 0.3677 & 3.2372 \\
\hline 75 & 11.3394 & 10.9457 & 0.3937 & 3.4720 \\
\hline 90 & 11.2750 & 10.8015 & 0.4735 & 4.1996 \\
\hline 105 & 11.1948 & 10.7319 & 0.4629 & 4.1350 \\
\hline 120 & 11.2106 & 10.7447 & 0.4659 & 4.1656 \\
\hline
\end{tabular}




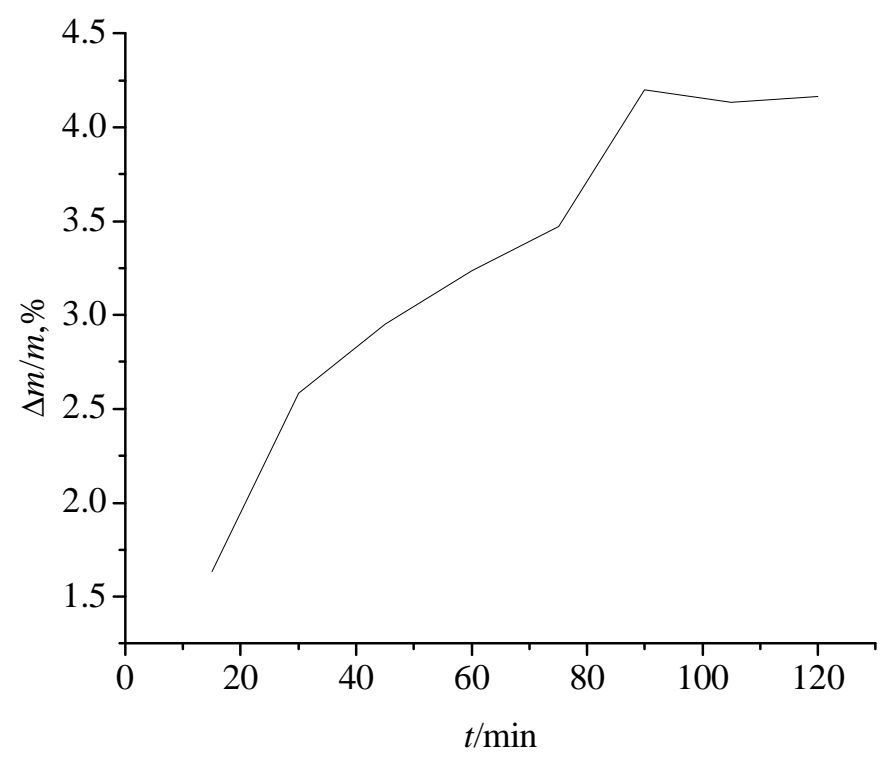

Fig. 4 Time and weight loss of sample during soaking

(2) Shorten the time interval of the water is $5 \mathrm{~min}$, the weight loss rate of the control powder, and the other is above, the quality change as shown in table 7.

Table 7 Changes in the quality of powder in the process of water immersion (interval $5 \mathrm{~min}$ )

\begin{tabular}{ccccc}
\hline $\begin{array}{c}\text { Water boiling time } \\
\mathrm{t} / \mathrm{min}\end{array}$ & $\begin{array}{c}\text { Pre cook weight } \\
\mathrm{m} / \mathrm{g}\end{array}$ & $\begin{array}{c}\text { Cook back weight } \\
\mathrm{m} / \mathrm{g}\end{array}$ & $\begin{array}{c}\text { Weightlessness } \\
\Delta \mathrm{m} / \mathrm{g}\end{array}$ & $\begin{array}{c}\text { Weight loss rate } \\
\Delta \mathrm{m} / \mathrm{m} / \%\end{array}$ \\
\hline 5 & 10.5241 & 10.4298 & 0.0943 & 0.8960 \\
10 & 12.0980 & 11.9571 & 0.1409 & 1.1646 \\
15 & 11.1281 & 10.9640 & 0.1641 & 1.4746 \\
\hline
\end{tabular}

From the experimental results, the triple-base propellant weight loss control in less than $3 \%$, the soaking time should control in 10 60min, however, soaking time determined should also be combined with the back combustion performance test.

\section{Preliminary determination of soaking conditions}

Through the above experiments, the preliminary determination conditions are as follows: Water extract: do not change in the soaking process; Water: more than 5 times the mass of the propellant; Temperature control: 100, micro boiling state; Time: 10 60min.

\section{Conclusions}

In this paper, the process flow of the treatment of the water immersion in the treatment of nitro drug delivery was studied, and the weight loss of the propellant in the process of immersion was analyzed.

(1) It is advisable to use the solution of the water flooding, which can avoid the destruction of the structure of the propellant after immersion in water;

(2) Soaking temperature should be 100 , because the solubility of the nitro group at 100 is the highest, which can improve the efficiency of water immersion;

(3) According to the solubility of nitroguanidine in boiling water immersion, the quality should be 
greater than 5 times the mass of propellant;

(4) The continuous use of the extract technology is more conducive to improve production efficiency;

(5) In order not to affect the energy and mechanical properties of the propellant, the immersion time should be controlled within the $60 \mathrm{~min}$..

\section{References}

[1] Zhang Xingfen compilation. Foreign powder raw material performance Handbook [M]. Beijing: Weapon Industry Press.1991.11.

[2] edited by Zhang Duanqing. Powder material performance of [M]. Beijing: Beijing Institute of Technology press.1995.1.

[3] Zhou Qinghuai, the task is. [M]. Beijing: National Defense Industry Press,.1983.

[4] Zhao Baochang, Xing Yuren, Deng Qingcai, et al. Nitroguanidine propellant [M]. Weapon Industry Press.1989.11.

[5] Duan Jun. Sanji emission medicine half solvent process intermittent feeding way of kneading of process and product performance [J]. Chinese Journal of explosives and propellants.2003.11 $(11-15)$. 